\title{
The bad and the ugly: a systematic review of technology's negative impacts' mentions in literature from 2005 to 2020
}

\author{
Inês T. Silva, Luís F. Rodrigues, Marta M. Sampayo
}

Instituto Universitário de Lisboa (ISCTE-IUL), Lisboa, Portugal.

\begin{abstract}
In an era of ubiquitous presence of several formats of technology throughout all areas of human interaction, it seems pertinent to assess the complete spectrum of possible impacts such technologies may have: not just the good, but the bad and the ugly too. Scientific research has been substantial on its efforts to map technology's benefits from which humans may profit on a myriad of activities. This is particularly evident in recent fields of study, such as gamification applications to marketing, education or business. However, it could be argued that in-depth analysis of potential nefarious impacts of technology use is currently lacking. In this paper, we perform a systematic review of contributions from top scientific publications over the last fifteen years in search of their concerns over the implementation and usage of technology, to gather proof that this is a promising study field, which deserves further study. Due to the limited literature and empirical evidence on the topic, this study contributes to better understand of nefarious impacts and limitations of technology.
\end{abstract}

Keywords: Technology; Negative impacts; Dark side of technology; Systematic study; Technostress. 


\section{Introduction}

We monitor our health and fitness with a smart-watch, we choose where we will be having lunch online, register it on our social network pages and comment on the food on the restaurant's social network pages, we get our news from Twitter and Google notifications, make our doctor appointments through an app, we unwind from a tough work day including several screen hours by watching a series or a movie on a streaming platform of our choice, we buy online and receive notifications of when to sleep and drink water, all the while emailing and direct messaging each other several times throughout the day. We use technology so much and on so many levels on our daily lives, our jobs, our family life and our entertainment purposes, that it could be argued technology has become, in fact, a part of ourselves. "We are not living in isolation from our contemporary society and culture, from our contemporary environment, and this is a technological environment with specific features." (Coeckelbergh, 2018 pg. 8).

Whilst the positive outcomes of technology, its uses and potential advantages have been largely targeted on several studies throughout the last two years, we would like to look in a different direction and question its potential negative impacts on people and society and related ethical questions. The need to understand the way in which technology impacts our lives was prescribed by Pleasants et al (2019) on their studies about the relationship between science and technology, which sought to map the fundamental issues surrounding the Nature Of Technology and what the scientific community has been pointing as their main concerns about it in the area of educations studies. Out of ten questions asked by Pleasants (2019), two concern the need to understand how technology affects the way people think and behave as well as how it influences society, moving away from an oversimplifying means-end approach for the relationship human-technology.

With this study, our aim is to sustain the importance and utility of investigating potential limitations and negative effects that may arise from the use of gamification and gamified artefacts. The focus of investigation efforts on individual cases with positive outcomes can be seen an oversimplification, and gamification has been pointed out as a field requiring a broader perspective including not only consideration on the positive, but the acknowledgement of the negative "We should move our attention from tackling limiting problems to study and understand harmful issues" (Hyrynsalmi, Smed, \& Kimppa, 2017). The volume of studies on this matter, however, seems to not be large. In this sense, we propose to justify the need for its exploration by assessing whether the scientific community's studies have been addressing potential negative impacts that technology may have. Our hypothesis can be explained by the outline of a simple causal relation: if there is a generalized concern with potential negative effects of technology in people's lives, then as gamification is used in technology design, there is a need for studying its potential negative effects as well. For this hypothesis, we will consider that the degree of concern of the scientific community 
can be apprised by considering the number of scientific articles published on top journals (Q1 and Q2) either which were written about a negative impact of a technology or which tried to cover the full specter of impacts of a technology, including negative ones.

For this purpose, we will perform a systematic review of the literature from 2005 to 2020, following the structured approach recommended by Webster \& Watson (2002) for investigation in Information Systems research. (Kasurinen \& Knutas, 2018; Rodrigues, Oliveira, \& Rodrigues, 2019; Subhash \& Cudney, 2018). We will start by reviewing some ethical concerns about the interaction between humans and technology, technologies' life cycle and potential negative effects of technology. We will discuss the final sample of texts obtained by this study in light of the existing literature, its potential limitations and we will suggest some paths for future investigations.

\section{Background}

\subsection{Some ethical concerns about technology}

There have been prior studies concerning the relationship between humans and technology and its ethical surrounding: Verbeek (2011) has looked in depth into the ethical questions surrounding technology in order to initiate a "third turn" on ethical and morality studies concerning technology, one that sees technology as a mediator of human moral behaviour. In this perspective, technology creates ethical conundrums that directly depend on its use and would not have arisen without it, as well as the issues where technology is designed to change people's moral behaviour, which implies to responsibility for morality lying on both the designer's and the user's side. Designers should be aware that the technology they have thought out to have one specific effect on people's behaviour may have additional undesirable effects that should be accounted for; and users should be aware of the technology they are buying into. From this second type of mediation arises the assumption that individuals have the necessity and duty of defining for themselves how they wish to interact with technology, as opposed to blindly embracing it or rejecting it (Soltanzadeh, 2012). For this intent, we argue that in order to make reasoned choice, individuals should have access to information on the possible pitfalls of using a specific technology, as well as of its potential and capabilities.

\subsection{Technology's lifecycle}

The dawn of emerging technologies is often celebrated, however, with the investigative and informative focus pointed at the positive sides and promising effects of said technology. There is a tendency for its creators and promotors to overestimate it, seldom paying attention to its potential limitations and inefficacies; Landers (2019) calls it an irrational faith on the emerging technology. There is an initial phase when the brand-new technology is presented 
to the world, in which there are attempts to apply it to every possible area, including those in which it is later discovered that it bears little to no efficacy, which eventually leads to a general disappointment with it, sometimes causing its disappearance. The technologies that survive this crash eventually return to the public's interest with a fresh perspective and built their way to stability and to the everyday life (Landers, 2019).

O'Leary (2008) suggests that scientific studies on technology follow Gartner's Hype Cycle, as a higher concentration of certain types of studies can be found according to the Hype Cycle phase that it was going through at the time. O'Leary (2008) concluded that initial stages of an emergent technology usually see mostly studies on prototypes and technology's behaviour, whilst case studies often start appearing once it reaches the trough of disillusionment. From our point of view, an analysis of Gartner's Hype Cycle curve provides some sustenance to the assumption that questions on the potential negative impacts of technology, or of a technology artefact, do have a place in its evolution path. In fact, this seems to already be a concern in the non-scientific world, as a few books have been published where authors take an inquisitive look into the matter, often assuming a 'make it or break it' position towards it: either advocating for its use, or prescribing its complete abandonment, as the titles in Figure 2 suggest.

Who Can You Trust? How Technology Brought Us Together and Why It Might Drive Us Apart

The Shallows: What the Internet Is Doing to Our Brains

The Glass Cage: Where Automation Is Taking Us

Automating Inequality: How High-Tech Tools Profile, Police, and Punish the Poor

Habeas Data: Privacy Vs. the Rise of Surveillance Tech

Rise of the Robots: Technology and the Threat of a Jobless Future

Winners Take All: The elite Charade of Changing the World

What Technology Wants

You Are not a Gadget: A Manifesto

Weapons of Math Destruction: How Big Data Increases Inequality and Threatens Democracy

A Deadly Wandering: A Tale of Tragedy and Redemption in the Age of Attention

Alone Together: Why We Expect More From Technology and Less From Each Other

Technically Wrong: Sexist Apps, Biased Algorithms, and Other Threats of Toxic Tech
R. Botsman 2017

N. Carr 2011

N. Carr 2015

V. Eubanks 2015

C. Farivar 2018

M. Ford 2015

A. Giridharadas 2018

K. Kelly 2010

J. Lanier 2011

C. O’Neil 2017

M. Richtel 2014

S. Turkle 2012

S. Wachter-Boettcher 2017

Figure 1. Recent general audience books with substantial NOT themes. Source: Pleasants, Clough, Olson, \& Miller (2019).

More importantly though, it matters to assess how scholars have been approaching the negative effects of technology. What studies have been produced on this field, and what types of studies are there? The aim of this study is to review the most recent top scientific literature 
in order to assess whether the negative effects of technology have been subject to study and to the concern of the scientific community. We expected to compile a significant number of scientific texts from top publications in which the purpose of the study was to assess or explore potential impacts that several types of technology may have on people's lives, from several different study fields.

\subsection{About gamification}

Since our final aim is to provide sustenance to the assumption that it is pertinent to systematically investigate the potential negative effects and shortcomings of gamification and its applications, it now matters to provide a theoretical framework for gamification. Gamification can be understood as a process through which game elements are added to gameless objects or situations in order to support attributes which will bring them closer to games (Yohannis et al., 2014). Another definition of gamification, and one widely cited in the literature, is to see it as using game elements to non-game contexts (Deterding et al., 2011). There is also an instrumentalist definition of gamification, being described as referring to a technology that uses games elements or game layers (Rodrigues et al., 2019) such as social interaction as a means to promote individual's intrinsic motivation to perform a certain activity (Hamari \& Koivisto, 2015).

Despite the high volume of research found about gamification and its applications, there seems to be little effort to the study of its potential ethical conundrums (Kim \& Werbach, 2016). Some have suggested the need to deepen the scope of investigations in order to include concerns about gamification as well as benefits (Brigham, 2015). In addition, there are authors who alert to the possibility of gamification leading to the same types of ethical issues that games have been rising, namely in the contexts of addition or of its use in labor contexts which might allow for attempts of exploration (Hyrynsalmi et al., 2017). Moreover, exploitationware has been used to describe gamification by one of its fiercest critics, Iain Bogost (2013), who mostly attacks its use to replace material incentives in the workplace. These seems to suggest that, in fact, further studies of the potential shortcomings and negative effects of gamification are needed. To further support this view, we may take the work of Koivisto \& Hamari (2019) which pointed out the potential negative, adverse or nonpreferable effects of gamification as one of the 15 possible paths of investigation on gamification.

\section{Methodology}

In order to reach this goal, we have thus performed a systematic literature review using Scopus, Web of Science, EDS, Google Scholar and B-on content aggregation platform, using the following keywords and keyword combinations: 
- "negative effects" OR "negative impacts" OR "harmful effects" OR "counterproductive effects" AND "technology" OR "gamification" OR "games" OR "social media"; "technostress";

- “dark" OR “dark side” AND "technology” OR "gamification" OR "social media";

- "dark web";

- "dark side" AND "web".

These terms have been searched for on titles, abstracts and keyword sections, for a restricted period comprising the last 15 years; only articles from 2005 to 2020 were considered. Citing articles and referenced articles have also been reviewed for each relevant article identified by the researcher, which led to the consultation of different text subjects, which had not been initially identified by the search. The final compilation of texts, resulting from the abovedescribed process, was then subject to filtering based its type, preferring scientific journal articles to conference proceedings papers; no periodic articles were considered in this research. Furthermore, journal articles were chosen according to the relevance of the publication in which they were included and only the ones from top publications - from Q1 or Q2 in 2017 and 2018 - were kept in order to ensure quality of the information, based on Webster \& Watson's (2002) premise of major contributions pertaining to top publications. Two papers from the proceedings of scientific conferences were also considered for this study. Researcher's discretion and best knowledge has been used in the final selection of the texts to consider in this analysis.

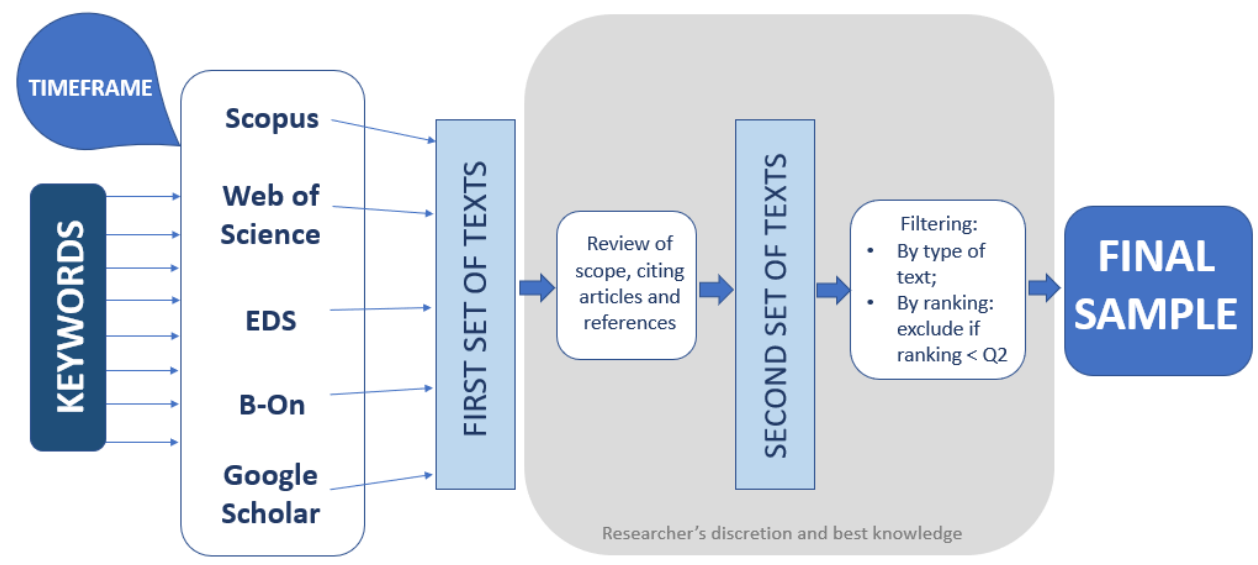

Figure 2. Methodology used for this paper.

Further to the selection and filtering process as explained o Figure 3, we had achieved a sample of scientific texts which content spanned from the study of human interaction with computers, to the effect of technology on people's mental health, to the influence technology may have on individuals' attitudes and the use of algorithms for media and politics. 
This body of texts' reliability and scientific relevance is derived from the fact that they have been peer reviewed and published in some of the top scientific journals of their respective fields.

Table 1 - Texts resulting from research and filtering by date and relevance of publication criteria.

\begin{tabular}{|c|c|c|c|c|}
\hline Theme & $2019-2020$ & $2015-2018$ & $2011-2014$ & $2007-2010$ \\
\hline Gamification & $\begin{array}{l}\text { Trang, S. and Weiger, } \\
\text { W. H. } \\
\text { Diefenbach, S. and } \\
\text { Müssig, A. } \\
\text { Landers, R. N. }\end{array}$ & $\begin{array}{l}\text { Keusch, F. and Zhang, C. } \\
\text { Kim, T. W. and Werbach, K. Imlig- } \\
\text { Iten, N. \& Petko, D. } \\
\text { Woodcock, J. and Johnson, M. R. } \\
\text { Leclercq, T., Hammedi, W. \& Poncin, I. }\end{array}$ & Dale, S. & N/A \\
\hline $\begin{array}{l}\text { Mental } \\
\text { Health }\end{array}$ & $\begin{array}{l}\text { Moor, L. and Anderson, } \\
\text { J. R. } \\
\text { Al-Rawi, A. } \\
\text { Doty, D. H. et al. }\end{array}$ & $\begin{array}{l}\text { Enez Darcin, A. et al. } \\
\text { Lowe-Calverley, E. and Grieve, R. } \\
\text { Laconi, S. et al. } \\
\text { Toner, J. } \\
\text { Carbonell, X. et al } \\
\text { Genni et al } \\
\text { Vahedi, Z. and Saiphoo, A. } \\
\text { Sampasa-Kanyinga, H., \& Lewis, R. F. }\end{array}$ & Lee, Y. K. et al. & $\begin{array}{l}\text { Charlton, J.P. } \\
\text { and Danforth, I. } \\
\text { D. W. }\end{array}$ \\
\hline Education & $\begin{array}{l}\text { Qi, C. } \\
\text { Wang, X. Tan, S. C. \& } \\
\text { Li, L. } \\
\text { Garzón, J., \& Acevedo, } \\
\text { J. Xu, Z., Banerjee, M., } \\
\text { Ramirez, G., Zhu, G., \& } \\
\text { Wijekumar, K. }\end{array}$ & $\begin{array}{l}\text { Patterson, R. W. and Patterson, R. M. } \\
\text { Chauhan, S } \\
\text { Kates, A. W., Wu, H., \& Coryn, C. L. S. }\end{array}$ & $\begin{array}{l}\text { Christy, K. R. and Fox, J Schmid, R. } \\
\text { F., Bernard, R. M., Borokhovski, E., } \\
\text { Tamim, R. M., Abrami, P. C., Surkes, } \\
\text { M. A., ... Woods, J }\end{array}$ & N/A \\
\hline Technostress & N/A & Maier, C. et al. & $\begin{array}{l}\text { Grover, V. and Purvis, R. Fuglseth, A. } \\
\text { M. and Sorebo, } \emptyset \text {. }\end{array}$ & $\begin{array}{l}\text { Tarafdar, M., Tu, } \\
\text { Q. and Ragu- } \\
\text { Nathan, T. Burke, } \\
\text { M. S. }\end{array}$ \\
\hline Social Media & $\begin{array}{l}\text { Linvill, D. L. } \\
\text { Sanz-Blas, S., Buzova, } \\
\text { D. and Miquel-Romero, } \\
\text { M. J. Sands, S. et al. }\end{array}$ & $\begin{array}{l}\text { Fox, J. and Moreland, J. J. } \\
\text { Maier, C. et al. } \\
\text { Satici, S. A. and Uysal, R. } \\
\text { Brooks, S. } \\
\text { Loiacono, E. and MeCoy, S. }\end{array}$ & $\begin{array}{l}\text { Carpenter, C. J. } \\
\text { Turel, O. and Serenko, A. Bucher, E., } \\
\text { Fieseler, C. and Suphan, A. } \\
\text { Dredge, R. Gleeson, J. and De La } \\
\text { Piedad Garcia, X. }\end{array}$ & N/A \\
\hline Security & N/A & $\begin{array}{l}\text { Feri, F., Giannetti, C. and Jentzsch, N. } \\
\text { Finklea, K. } \\
\text { Jardine, E. } \\
\text { Raguseo, E. }\end{array}$ & $\begin{array}{l}\text { Bucher, T. } \\
\text { O'Donnell, C. } \\
\text { Boyd, D. and Crawford, K. }\end{array}$ & N/A \\
\hline Sociology & N/A & $\mathrm{N} / \mathrm{A}$ & Dotson, $\mathrm{T}$. & N/A \\
\hline Media & Millar, B. & $\begin{array}{l}\text { Baruh, L. and Popescu, M } \\
\text { Spohr, D. }\end{array}$ & Beam, M. A. & N/A \\
\hline Marketing & N/A & Park, M., Im, H. and Kim, H. Y. & N/A & N/A \\
\hline Smartphones & N/A & $\begin{array}{l}\text { Enez Darcin, A. et al. } \\
\text { Carbonell, X. et al } \\
\text { Vahedi, Z. and Saiphoo, A. }\end{array}$ & Lee, Y. K. et al. & N/A \\
\hline Politics & N/A & Dylko, I et al. & N/A & N/A \\
\hline
\end{tabular}

\section{Results}

The outcomes of this research are shown on Table 1: 67 research pieces, 61 of which consist in scientific journal articles published on the top scientific journals of their fields. The articles compiled are linked to several scientific areas, spanning from health and psychology to computer science, marketing, politics and media.

From the texts selected as per criteria explained in Figure 3, we ended up with a final sample, $92 \%$ of which is composed of peer reviewed scientific journal articles against $5 \%$ texts representing papers from the proceedings of scientific conferences. The remainder $3 \%$ 
correspond to a single Government issued paper from a specialist on Domestic Security from the U.S. Congressional Research Service.

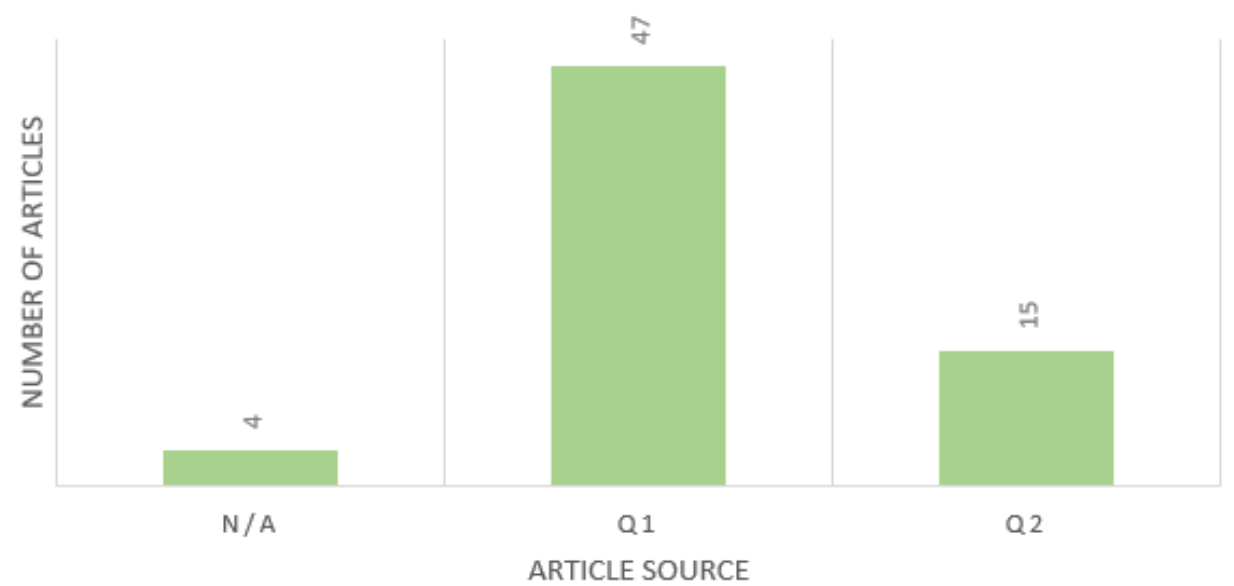

Figure 3. Number of articles by source ranking.

Although the research was performed for a restrict period comprising the last decade and a half (2005 to 2020 inclusively) the data seems to depict an increase of interest in the topics of potential negative impacts and effects of technology throughout, which according to this data spiked circa 2018 and 2019. It should be noted that the fact that 2020 is merely in its beginning most likely accounts for the small number of articles sourced for the purpose of this article. From the online databases and content aggregation portals utilized for this research, only Scopus' database considers articles still in press, which translates to the low representation in 2020.

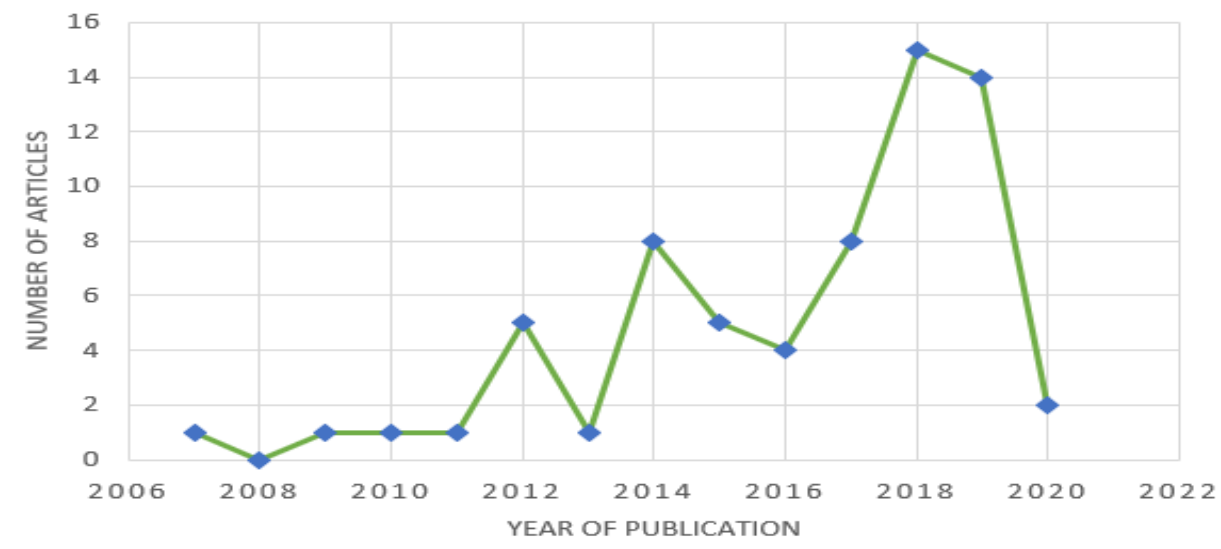

Figure 4. Number of articles per year. 
Social media seems to be the main point of concern for these studies, with twelve out of the 67 being on this topic and often taking on a psychological angle. Education is also an area of concern, with eight out of 67 studies on educational topics and adding to the seven items concerning games and gamification. Five of the 67 studies refer to the concept of technostress, which is defined by Trafdar et al (2011) as a work phenomenon caused by techno-overload, techno-invasion, techno-complexity, techno-insecurity and technouncertainty which leads to negative feelings towards technology such as a compulsion about being permanently online, forced to respond and trapped in a multitasking loop. There are also some items concerning the media and security and data protection, although in less number than the aforementioned areas.

\section{Discussion}

The final sample of scientific texts obtained in this study seems to provide a close portrait of the scientific community's views on the negative effects of technology, as it fulfils the requirements needed for a systematic literature review. We have defined clear boundaries for the period to which our sample should pertain, as well as the keywords for the search and the platforms, which would be used in order to obtain it. The texts retrieved for this study cover an array of scientific areas, as per Webster \& Watson (2002) recommendations for research on Information Systems' field "Because IS is an interdisciplinary field, you often must look not only within the IS discipline when reviewing (...) but also outside the field." (Webster \& Watson, 2002, pg. xvi). Texts from top ranked publications account for $92 \%$ of the final sample, and both its references and citing papers have been reviewed and considered for the scope of this study. (Wohlin \& Prikladniki, 2013). Finally, only recent texts - from 2005 to 2020 - have been considered for this research, thus accounting for the contemporary concerns of the scientific community.

Our results show that, whilst systematic reviews are lacking, specific area studies do show a concern about technology's impacts. With a final sample of 67 texts mentioning or deepening potential negative impacts of technology we seem to have obtained confirmation that, in fact, this is a valid and necessary angle to study technology. Top journals have been publishing articles which either directly approach a specific adverse effect of technology in human life, or it does so by studying impacts in a broader sense. We must, however, consider that the researcher's judgement had a significant impact on the final sample obtained, which means that this review is not free of some subjectivity; this being, it is possible that different researchers had produced a different set of texts as the outcome of a similar process (Wohlin $\&$ Prikladniki, 2013). Furthermore, there is also the fact that a closed set of search engines and platforms were used for the retrieval of these texts. Together with the degree of subjectivity mentioned, these results in the possibility of missing some important article, which could have been mentioned in the final sample. The keywords chosen a priori could 
also be a limitation in this study, as their combination might not be enough to target all the articles discussing the topics of interest. It is also a possibility that there are studies, which, despite discussing negative impacts of technology, do not mention any of the keywords on its title, abstract, keywords or final section. It is almost certain that some articles have been missed by this study (Webster J. \& Watson, 2002). We cannot thus be sure that our sample is the definite one, and further research would likely shape it differently. Studies following this one could take the review a step further and use the studies from our sample to perform a concept mapping, by use of text mining techniques in order to obtain a lexicon for the negative effects of using technology.

\section{Conclusion}

This study has investigated technology from a slightly darker point of view. We have proposed to assess the concerns of the community about its potential adverse effects on people's lives. Our findings can lead to deeper investigation on the potential adverse impacts of gamification and the application of gamified artifacts. Our purpose, which we believe was successfully fulfilled, was to aggregate theoretical grounds sustaining the need and scientific relevance for such a study. Thus, this paper provides a starting point for further studies into technologies' potential shortcomings. It shows that there has been concern in the scientific community about this topic, and that it has been intensifying over the last couple of years. Next steps on this path should include a review of the scientific community's thoughts about negative sides of gamification, as well as the application of quantitative techniques such as machine learning to obtain data that allows the definition of a solid theoretical framework on the subject. Further transversal studies on the potential negative effects of one particular technology or the mapping of mediator and moderator variables capable of mitigating the discovered adverse effects could also be derived from ours, as well as deeper transversal studies about the concept of dark technology.

\section{Acknowledgment}

This work was undertaken at ISTAR-Information Sciences and Technologies and Architecture Research Center from ISCTE-Instituto Universitário de Lisboa (University Institute of Lisbon), Portugal, and it was partially funded by the Portuguese Foundation for Science and Technology (Project "FCT UIDB/04466/2020").

\section{References}

Brereton, P., Kitchenham, B. A., Budgen, D., Turner, M., \& Khalil, M. (2007). Lessons from applying the systematic literature review process within the software engineering domain. Journal of Systems and Software. https://doi.org/10.1016/j.jss.2006.07.009 
Brigham, T. J. (2015). An Introduction to Gamification: Adding Game Elements for Engagement. Medical Reference Services Quarterly, 34(4), 471-480. https://doi.org/10.1080/02763869.2015.1082385

Coeckelbergh, M. (2018). Technology and the good society: A polemical essay on social ontology, political principles, and responsibility for technology. Technology in Society, 52, 4-9. https://doi.org/10.1016/j.techsoc.2016.12.002

Deterding, S., Dixon, D., Khaled, R., \& Nacke, L. (2011). From game design elements to gamefulness. https://doi.org/10.1145/2181037.2181040

Hamari, J., \& Koivisto, J. (2015). Why do people use gamification services? International Journal of Information Management. https://doi.org/10.1016/j.ijinfomgt.2015.04.006

Hyrynsalmi, S., Smed, J., \& Kimppa, K. K. (2017). The dark side of gamification: How we should stop worrying and study also the negative impacts of bringing game design elements to everywhere. CEUR Workshop Proceedings, 1857(May), 96-104.

Kasurinen, J., \& Knutas, A. (2018). Publication trends in gamification: A systematic mapping study. Computer Science Review. https://doi.org/10.1016/j.cosrev.2017.10.003

Kim, T. W., \& Werbach, K. (2016). More than just a game: ethical issues in gamification. Ethics and Information Technology, 18(2), 157-173. https://doi.org/10.1007/s10676016-9401-5

Pleasants, J., Clough, M. P., Olson, J. K., \& Miller, G. (2019). Fundamental Issues Regarding the Nature of Technology: Implications for STEM Education. Science and Education, 28(3-5), 561-597. https://doi.org/10.1007/s11191-019-00056-y

Rodrigues, L. F., Oliveira, A., \& Rodrigues, H. (2019). Main gamification concepts: A systematic mapping study. Heliyon, 5(7), e01993. https://doi.org/10.1016/j.heliyon.2019.e01993

Soltanzadeh, S. (2012). Peter-Paul Verbeek's Moralizing Technology: Understanding and Designing the Morality of Things. NanoEthics, 6(1), 77-80. https://doi.org/10.1007/s11569-012-0143-5

Subhash, S., \& Cudney, E. A. (2018). Gamified learning in higher education: A systematic review of the literature. Computers in Human Behavior, 87. https://doi.org/10.1016/j.chb.2018.05.028

Webster J. \& Watson, R. (2002). Analysing the past to prepare the future: writing a literature review. MIS Quarterly, 26((2)), xiii-xxiii.

Wohlin, C., \& Prikladniki, R. (2013). Systematic literature reviews in software engineering. Information and Software Technology. https://doi.org/10.1016/j.infsof.2013.02.002

Yohannis, A. R., Denny Prabowo, Y., \& Waworuntu, A. (2014). Defining gamification: From lexical meaning and process viewpoint towards a gameful reality. 2014 International Conference on Information Technology Systems and Innovation, ICITSI 2014 - Proceedings, (November), 284-289. https://doi.org/10.1109/ICITSI.2014.7048279 